\title{
Identification of Proteins Responsible for the Development of Adriamycin Resistance in Human Gastric Cancer Cells Using Comparative Proteomics Analysis
}

\author{
Yi-Xuan Yang, Huai-Dong Hu, Da-Zhi Zhang and Hong Ren* \\ Key Laboratory of Molecular Biology for Infectious Diseases, Ministry of Education of China, The Second Affiliated Hospital, \\ Chongqing Medical University, Chongqing 400010, PR China
}

Received 26 March 2007, Accepted 8 June 2007

Resistance to anticancer drugs is a major obstacle in the effective treatment of tumors. To understand the mechanisms responsible for multidrug resistance (MDR), a proteomic approach was used to identify proteins that were expressed in different levels by the adriamycinresistant human gastric cancer cell line, SGC7901/ADR, and its parental cell line, SGC7901. Two-dimensional gel electrophoresis (2-DE) and image analysis was used to determine which protein spots were expressed in different levels by the two cell lines. These spots were then partially identified using ESI-Q-TOF mass spectrometry, and the differential expressional levels of the partially identified proteins were then determined by western blot analysis and real-time RT-PCR. Additionally, the association of Nucleophosmin (NPM1), a protein that was highly expressed by SGC7901/ADR, with MDR was analyzed using siRNA. As a result of this study, well-resolved, reproducible 2-DE patterns of SGC7901/ADR and SGC7901 were established, and 16 proteins that may play a role in the development of thermoresistance were identified. Additionally, suppression of NPM1 expression was found to enhance adriamycin chemosensitivity in SGC7901/ ADR. These results provide a fundamental basis for the elucidation of the molecular mechanism of MDR, which may assist in the treatment of gastric cancer.

Keywords: Gastric cancer, Mass spectrometry, Multidrug resistance, Nucleophosmin, Proteome analysis, Two-dimensional gel electrophoresis
* To whom correspondence should be addressed.

Tel: 86-23-66921007; Fax: 86-23-63822696

E-mail; renhong0531@vip.sina.com.cn

\section{Introduction}

Multidrug resistance (MDR) is a phenomenon in which crossresistance of tumor cells to several structurally unrelated chemotherapeutic agents develops after exposure to a single cytotoxic drug. Tumor cells that exhibit MDR show decreased cellular sensitivity to a broad spectrum of drugs, therefore MDR is often the reason chemotherapy of malignant tumors, including those associated with gastric cancer, fails. The multidrug-resistant gastric cancer cell line, SGC7901/ADR, was derived from the human gastric cancer cell line, SGC7901, by stepwise selection in vitro using adriamycin (ADR) as an inducing reagent. SGC7901/ADR is a useful model for elucidation of the mechanism underlying MDR in gastric cancer, and can also be used to study cross-resistance to other anticancer drugs, including cisplatin, etoposide, mitomycin C, and 5-fluorouracil (5-FU) (An et al., 1997; Zhao et al., 2002). Such multidrug resistance (MDR) is believed to be partially due to overexpression of P-glycoprotein, which functions as a transmembrane efflux pump that uses two ATP molecules to transport one drug molecule. However, treatment of SGC7901/ $\mathrm{ADR}$ with verapamil, a potent inhibitor of P-glycoprotein, did not restore full sensitivity of these cells to adriamycin, which indicates that other mechanisms might be involved in the development of resistance to the drug (Moscow et al., 1998; Kramer et al., 1998). Indeed, several mechanisms have been found to contribute to $\mathrm{MDR}$, including reduction of the intracellular accumulation of anti-cancer drugs as a result of increased drug efflux or decreased drug uptake (Lee et al., 2004; Yeh et al., 2004), alterations in drug targets (Stein et al., 2003), and activation of detoxifying systems (Depeille et al., 2005). In addition, increased repair of drug-induced DNA damage, blocked apoptosis, disruptions in signaling pathways, and alterations of factors involved in cell cycle control can also lead to multidrug resistance (Lelong-Rebel et al., 2004; Hong et al., 2005). A greater understanding of the molecular basis of gastric cancer chemoresistance is likely to provide 
more effective treatment for patients, therefore, in this study, a proteomics approach was used to examine the overall protein expression pattern of the SGC7901/ADR cell line. The results of this study are expected to reveal new proteins related to MDR, which may lead to a better characterization of the SGC7901/ADR cell line, and therefore a better understanding of its adriamycin resistant phenotype.

\section{Materials and Methods}

Reagents. IPG DryStrips (pH 3-10, $24 \mathrm{~cm}$ ), IPG buffer ( $\mathrm{pH} 3-10$ ), Pharmalyte (pH 3-10), PVDF membranes, goat anti-mouse, goat anti-rabbit IgG-conjugated with horseradish peroxidase, and the enhanced chemiluminescence (ECL) system were purchased from Amersham Biosciences, Stockholm, Sweden. Monoclonal antibodies against Annexin1(ANX1), Nucleophosmin (NPM1), Superoxide dismutase [Mn] (SOD2) and $\alpha$-Tublin were obtained from Santa Cruz Biotechnology.

Cell lines. The adriamycin-resistant human gastric carcinoma cell line SGC7901/ADR and its parental cell line, SGC7901, were provided as a gift from Dr. DM Fan (The Fourth Military Medical University). To maintain the biologic characteristics of $\mathrm{MDR}$, SGC7901/ADR was cultured in RPMI1640 medium containing 10\% fetal calf serum (Gibico BRL) and $0.8 \mathrm{mg} / \mathrm{l}$ adriamycin (SigmaAldrich).

Two-Dimensional Electrophoresis (2-DE). SGC7901/ADR and SGC7901 were lysed in lysis buffer (7 M urea, $2 \mathrm{M}$ thiourea, $100 \mathrm{mM}$ DTT, 4\% CHAPS, $40 \mathrm{mM}$ Tris, $2 \%$ Pharmalyte, $1 \mathrm{mg} / \mathrm{ml}$ DNase I), and then centrifuged at $15,000 \mathrm{rpm}$ for $30 \mathrm{~min}$ at $4^{\circ} \mathrm{C}$. The supernatant was then collected and the concentration of total proteins was determined using a 2D Quantification kit (Amersham Biosciences). Next, isoelectric focusing was carried out on an IPGphor system (Amersham Biosciences) using IPG strips (pH 3$10,240 \mathrm{~mm}^{*} 3 \mathrm{~mm} * 0.5 \mathrm{~mm}$ ). Second-dimension sodium dodecyl sulfate-polyacrylamide gel electrophoresis (SDS-PAGE) was then performed on an Ettan DALT II system (Amersham Biosciences), which was followed by Blue Silver staining to visualize the protein spots in the 2-DE gels (Candiano et al., 2004; Wang et al., 2006).

Image analysis. The stained 2-DE gels were scanned using the MagicScan software on an Imagescanner (Amersham Biosciences), and then analyzed using the PDQuest system (Bio-Rad laboratories) according to the manufacturer's protocols. To minimize the contribution of experimental variations, three separate gels were prepared for each cell line. The densities of the spots were determined after normalization based on the total spot volumes on the gel. Protein spots that showed significant changes in densities (paired $t$-test, $p \leq 0.05$ ) in a consistent direction (increase or decrease) were considered to be different and selected for further identification.

Protein identification. The 20 protein spots that showed differential expression were excised from the preparative gels, washed, destained, and dried, and then incubated in digestion solution ( $40 \mathrm{mM} \mathrm{NH}_{4} \mathrm{HCO}_{3}$ in $9 \%$ acetonitrile solution, and $20 \mu \mathrm{g} /$ $\mathrm{ml}$ proteomics grade trypsin) for $12 \mathrm{~h}$ at $37^{\circ} \mathrm{C}$. The samples were then analyzed using ESI-Q-TOF-MS (Micromass, Manchester, UK). An in tandem mass spectrometry data database query in the PKL format file that was generated as a result of the MS/MS analysis was imported into the Mascot search engine (http://www. matrixscience.com/), which was then searched using the following parameters: the taxonomy selected was all entries or homo sapiens; the mass tolerance selected was \pm 0.5 Dalton; the MS/MS tolerance selected was \pm 0.3 Dalton; the missed cleavage sites allowed were up to 1 ; the fixed modification selected was carboxymethyl (cysteine); the variable modification selected was oxidation (methylation) or none; the data format selected was Micromass PKL format; and the instrument selected was ESI-Q-TOF.

Western blot analysis. Total proteins were extracted from the cell lysates, and then loaded and separated on $12 \%$ SDS-PAGE. The proteins were then transferred to PVDF membranes and the amount of ANX1, NPM1 and SOD2 was then detected using anti-ANX1, anti-NPM1 and anti-SOD2, respectively. The results were then visualized using the ECL detection system. All western blot analyses were performed at least three times.

Real-time quantitative RT-PCR analysis. Quantitative RT-PCR was performed on the Roche LightCycler system (Roche Diagnostics, Mannheim, Germany) using SYBR Green I dye, which binds preferentially to double-stranded DNA. The specific primers used were 5'-tattggctatgattgacg-3' (sense) and 5'-cacagggtggtggtaaa-3' (antisense) for PPA1, 5'-tttacggacactgaacgg-3' (sense) and 5'atcttggtagcctgacg- $3^{\prime}$ (antisense) for HSC70, 5'-tattcagcaccagttcctc$3^{\prime}$ (sense) and 5'-cccaaaccaccattctt-3' (antisense) for PDX3, and 5'aatcccatcaccatcttcc-3' (sense) and 5'-catcacgccacagtttcc-3' (antisense) for GAPDH. The reaction conditions were as follows: denaturation at $95^{\circ} \mathrm{C}$ for $10 \mathrm{~s}$, followed by $40-45$ cycles at $95^{\circ} \mathrm{C}$ for $5 \mathrm{~s}, 52^{\circ} \mathrm{C}$ for $10 \mathrm{~s}$, and $72^{\circ} \mathrm{C}$ for $10 \mathrm{~s}$ with a single fluorescence measurement, after which a melting curve program was employed. Since the melting curve of a product is sequence specific, it can be used to distinguish between non-specific and specific PCR products. To verify the melting curve results, the PCR products were sequenced using a 377 Prism automated DNA sequencer (ABI). The relative quantification of gene expression was analyzed using the $2^{-\Delta 1 C T}$ method (Livak et al., 2001). Real-time quantitative RT-PCR analysis was repeated at least three times.

Administration of Nucleophosmin siRNA to cells. Cells were transfected with Nucleophosmin (NPM1) siRNA or control siRNA (Santa Cruz Biotechnology) according to the siRNA transfection protocol provided by the manufacturer. Briefly, when the cells were $60-80 \%$ confluent, they were transfected with $10 \mathrm{mM}$ of NPM1 siRNA or control siRNA after preincubation for $20 \mathrm{~min}$ with siRNA transfection reagent in siRNA transfection medium (Santa Cruz Biotechnology). Four hours after transfection was started, the medium was replaced with RPMI1640 medium containing 10\% fetal calf serum, and the cells were then cultured for an additional $44 \mathrm{~h}$. At the end of the transfection they were incubated with different concentrations of adriamycin for $24 \mathrm{~h}$, after which, the NPM1 expression level was determined by Western blot as described above, and the cell viability of SGC7901/ADR was examined using the 3-(4,5-dimethylthiazol-2-yl)-2,5-diphenyltetrazolium bromide (MTT) assay described by Plumb et al. (1989). 
Hoechst 33258 staining of apoptotic cells. The nuclear morphology of cells was studied using the cell-permeable DNA dye, Hoechst 33258 (Sigma-Aldrich). Cells with homogeneously stained nuclei were considered viable, whereas the presence of chromatin condensation and/or fragmentation was considered to indicate apoptosis. Hoechst staining was performed using the method described by Perez-Ortiz et al. (2004). Briefly, SGC7901/ ADR cells were transfected with $10 \mathrm{nmol} / 1$ of NPM1 siRNA or control siRNA. Two days after transfection, the cells were incubated with $0.8 \mathrm{mg} / \mathrm{l}$ adriamycin for an additional $48 \mathrm{~h}$, as described above. The cells were then harvested, washed, and fixed with methanol-acetic acid $(3: 1, \mathrm{v}: \mathrm{v})$ at room temperature for 10 $\min$. Following centrifugation, the cells were spotted onto slides and stained with $25 \mathrm{mg} / \mathrm{ml}$ Hoechst 33258 in the dark for $40 \mathrm{~min}$. After placing a drop of mounting medium on the slides, the cells were observed using an Olympus $\mathrm{BH}-2$ fluorescence microscope (Japan).

\section{Results}

Protein profiling and identification of differentially expressed proteins. To compare global protein profiles between adriamycin resistant SGC7901/ADR and its counterpart, SGC7901, we first conducted two-dimensional gel electrophoresis analysis of the total lysates prepared from these cell lines. Following Coomassie blue staining (Fig. 1), the gels were subjected to PDQuest imaging analysis. 2-DE maps of SGC7901/ADR and SGC7901 obtained between $\mathrm{pH} 3$ and 10 displayed approximately 1150 spots each. Twenty spots that were differentially expressed in SGC7901/ADR, as compared with SGC7901, were then chosen for further analysis (Fig. 1). The 20 differential protein spots were excised from the gels, digested with trypsin, and subsequently analyzed by ESI-QTOF-MS in combination with a database search. Mascot searches identified 16 of the spots (Fig. 1 and Table 1, spots 1$4,7-8,10-18$ and 20) with good peptide coverage and significant scores. Ten of these 16 protein spots were up- regulated by the treatment and 6 were down-regulated by the treatment. A representative MS/MS result of spot 12 is shown in Fig. 2. The amino acid sequence of a doubly charged peptide obtained from spot 12 with a $\mathrm{m} / \mathrm{z}$ of 1113.7327 was identified as MSVQPTVSLGGFEITPPVVLR, which is part of the Nucleophosmin (NPM1) sequence. Analysis of the spots also indicated that spot 12 was associated with NPM1. Overall, the differentially expressed proteins in the adriamycinresistant SGC7901/ADR cells were able to be divided into the following six groups based on their functions using information obtained from the Swiss-Prot and NCBInr websites: transportation, chaperones, calcium binding proteins, proteins involved in drug detoxification, metabolic enzymes, and proteins related to signal transduction.

Validation of differentially expressed proteins. In order to confirm the differential expression levels of the proteins identified using the comparative proteomics approach, the expressional levels of the partial proteins in SGC7901/ADR and SGC7901 were measured by Western blot analysis and real-time quantitative RT-PCR. Figure $3 \mathrm{~A}$ showed a representative Western blot analysis result of ANX1, NPM1 and SOD2 expression in the two cell lines. As seen in Fig. 3B, ANX1, NPM1 and SOD2 were obviously up regulated in SGC7901/ $\mathrm{ADR}$, which was identical to the results obtained by 2-DE (Fig. 3B). Figure 4 shows the relative mRNA expression levels of PPA1, HSC70 and PDX3 after normalization with GAPDH mRNA levels, as determined by real-time RT-PCR.

The association of Nucleophosmin with MDR. To study the functional role of Nucleophosmin (NPM1) up regulation in SGC7901/ADR, SGC7901/ADR cells were transfected with NPM1 siRNA, and siRNA-induced inhibition of NPM1 expression was then determined by Western blot analysis. As shown in Fig. 5A, transfection of SGC7901/ADR cells with NPM1 siRNA significantly reduced the NPM1 protein levels, whereas NPM1 protein expression was not significantly
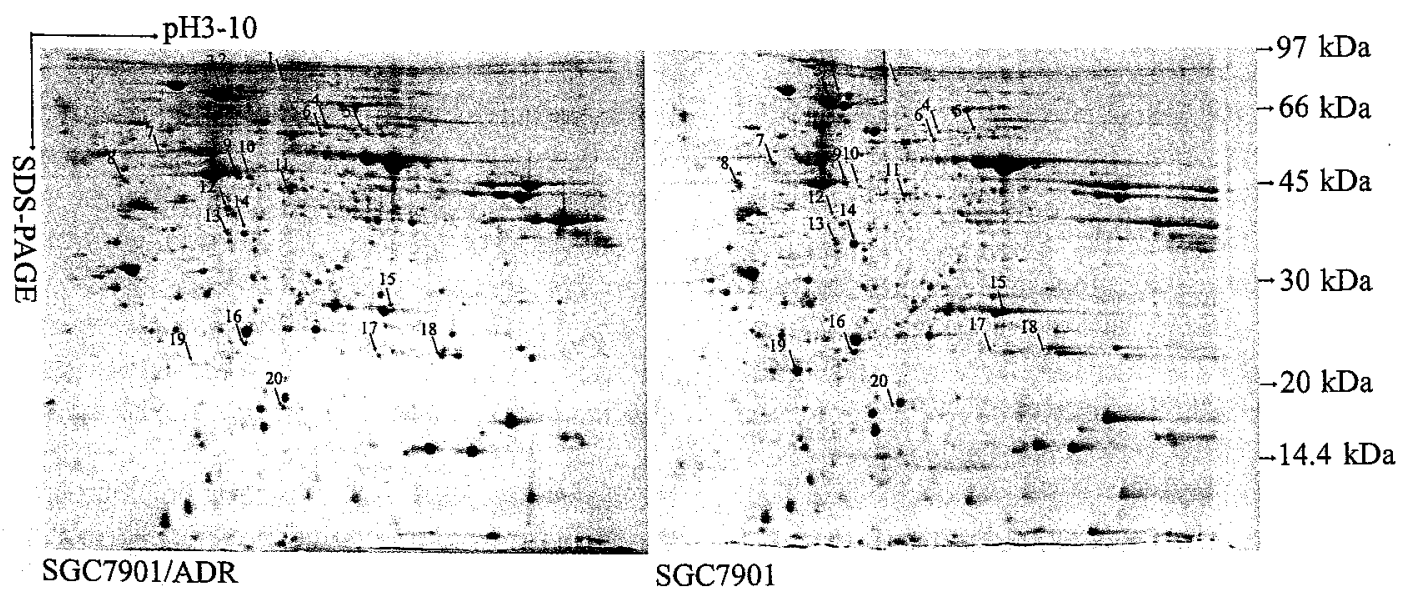

Fig. 1. Representative 2-DE maps of adriamycin-resistant SGC7901/ADR and SGC7901. The 20 differentially expressed protein spots are marked with arrows. 
Table 1. Comparison of ESI-Q-TOF-MS identified proteins in SGC7901/ADR vs. SGC7901

\begin{tabular}{|c|c|c|c|c|c|c|c|c|c|}
\hline \multirow{2}{*}{$\begin{array}{l}\text { Spot } \\
\text { No }\end{array}$} & \multirow{2}{*}{$\begin{array}{l}\text { Accession } \\
\text { number }\end{array}$} & \multirow{2}{*}{$\begin{array}{l}\text { Protein name } \\
\text { (Gene name) }\end{array}$} & \multirow[t]{2}{*}{$\% \mathrm{Cov}$} & \multirow[t]{2}{*}{ Score } & \multirow{2}{*}{$\begin{array}{l}\text { Mass } \\
(\mathrm{Da})\end{array}$} & \multirow[t]{2}{*}{$\mathrm{pI}$} & \multicolumn{2}{|c|}{$\begin{array}{l}\text { SGC7901/ADR vs. } \\
\text { SGC7901 }\end{array}$} & \multirow[t]{2}{*}{ Function } \\
\hline & & & & & & & Av.rati & -value & \\
\hline 1 & Q6GU03 & $\begin{array}{l}\text { Heat shock } 70 \mathrm{kDa} \text { protein } 9 \mathrm{~B} \\
\text { (HSPA9B) }\end{array}$ & 35 & 378 & 74093 & 6.04 & 3.20 & 0.001 & Chaperone \\
\hline 2 & P11021 & $\begin{array}{l}\text { Heat shock } 70 \mathrm{kDa} \text { protein } 5 \\
\text { (GRP78) }\end{array}$ & 48 & 421 & 72402 & 5.07 & 2.25 & 0.001 & Chaperone \\
\hline 3 & P11142 & $\begin{array}{l}\text { Heat shock cognate } 71 \mathrm{kDa} \text { pro- } \\
\text { tein } \\
\text { (HSC70) }\end{array}$ & 45 & 373 & 71082 & 5.37 & 2.13 & 0.001 & Chaperone \\
\hline 4 & P30837 & $\begin{array}{l}\text { Aldehyde dehydrogenase } X \\
\text { (ALDH1B1) }\end{array}$ & 57 & 389 & 57238 & 6.41 & 2.20 & 0.002 & Antioxidant \\
\hline 7 & P06576 & $\begin{array}{l}\text { ATP synthase subunit beta } \\
\text { (ATP5B) }\end{array}$ & 44 & 386 & 56560 & 5.26 & 0.45 & 0.001 & Metabolism \\
\hline 8 & Q15293 & $\begin{array}{l}\text { Reticulocalbin-1 } \\
\text { (RCN1) }\end{array}$ & 31 & 302 & 38866 & 4.86 & 0.50 & 0.001 & Calcium-binding \\
\hline 10 & P12277 & $\begin{array}{l}\text { Creatine kinase B-type } \\
\text { (CKB) }\end{array}$ & 42 & 472 & 42933 & 5.34 & 3.25 & 0.001 & Metabolism \\
\hline 11 & P04083 & $\begin{array}{l}\text { Annexin1 } \\
\text { (ANX1) }\end{array}$ & 40 & 295 & 38787 & 6.64 & 3.50 & 0.003 & Calcium-binding \\
\hline 12 & P06748 & $\begin{array}{l}\text { Nucleophosmin } \\
\text { (NPM1) }\end{array}$ & 28 & 276 & 32611 & 4.67 & 3.74 & 0.001 & Transportation \\
\hline 13 & P05388 & $\begin{array}{l}\text { Ribosomal protein } \mathrm{P} 0 \\
\text { (RPLP0) }\end{array}$ & 35 & 235 & 34424 & 5.42 & 0.50 & 0.010 & Signal transduction \\
\hline 14 & Q15181 & $\begin{array}{l}\text { Inorganic pyrophosphatase } \\
\text { (PPA1) }\end{array}$ & 39 & 398 & 33095 & 5.54 & 0.46 & 0.005 & Metabolism \\
\hline 15 & p60174 & $\begin{array}{l}\text { Triosephosphate isomerase } \\
\text { (TPI) }\end{array}$ & 45 & 471 & 26669 & 6.51 & 0.47 & 0.003 & Metabolism \\
\hline 16 & p32119 & $\begin{array}{l}\text { Peroxiredoxin-2 } \\
\text { (PRDX2) }\end{array}$ & 58 & 415 & 21892 & 5.19 & 0.51 & 0.013 & Antioxidant \\
\hline 17 & p30048 & $\begin{array}{l}\text { Peroxiredoxin-3 } \\
\text { (PRDX3) }\end{array}$ & 60 & 473 & 27693 & 7.67 & 2.50 & 0.001 & Antioxidant \\
\hline 18 & p04179 & $\begin{array}{l}\text { Superoxide dismutase [Mn] } \\
\text { (SOD2) }\end{array}$ & 50 & 394 & 24722 & 8.66 & 3.45 & 0.001 & Antioxidant \\
\hline 20 & 043169 & $\begin{array}{l}\text { Superoxide dismutase }[\mathrm{Cu}-\mathrm{Zn}] \\
\text { (SOD1) }\end{array}$ & 60 & 475 & 15936 & 5.87 & 2.50 & 0.009 & Antioxidant \\
\hline
\end{tabular}

Proteins found to be differentially labeled by 2-DE analysis were identified by ESI-Q-TOF-MS. The Swiss-Prot accession number, the $\%$ coverage of analyzed peptides, the score from Mascot searches, the Mass and pI from the database, and an average fold-difference between pairs (paired $t$-test, $p 0.05$ ) are shown for each protein.

suppressed by the control siRNA. We next evaluated the effect of NPM1 siRNA transfection on the adriamycin chemosensitivity of SGC7901/ADR. SGC7901/ADR cells were treated with NPM1 siRNA for 2 days, and then incubated for an additional $24 \mathrm{~h}$ with different concentrations of adriamycin. The cell viability of SGC7901/ADR was then examined using a MTT assay. As shown in Fig. 5B, transfection of SGC7901/ADR cells with NPM1 siRNA enhanced adriamycin chemosensitivity, which led to a significant decrease in cell viability. Figure $5 \mathrm{C}$ also shows that NPM1 siRNA transfection significantly decreased the cell viability of SGC7901 cells incubated with adriamycin. Finally, induction of apoptosis by NPM1 siRNA was demonstrated by using the cell-permeable DNA dye Hoechst 33258. After being treated for $48 \mathrm{~h}$ with $0.8 \mathrm{mg} / \mathrm{l}$ adriamycin, SGC7901/ ADR cells exhibited apoptosis features consisting of chromatin condensation in cell nuclei (Fig. 5D), which clearly demonstrated that NPM1 siRNA could enhance adriamycin chemosensitivity.

\section{Discussion}

In this study, we used a proteomic approach to identify proteins that were differentially expressed in the adriamycinresistant human gastric cancer cell line, SGC7901/ADR, and its parental cell line SGC7901. We observed 20 protein spots that showed significant differences in expression between the 


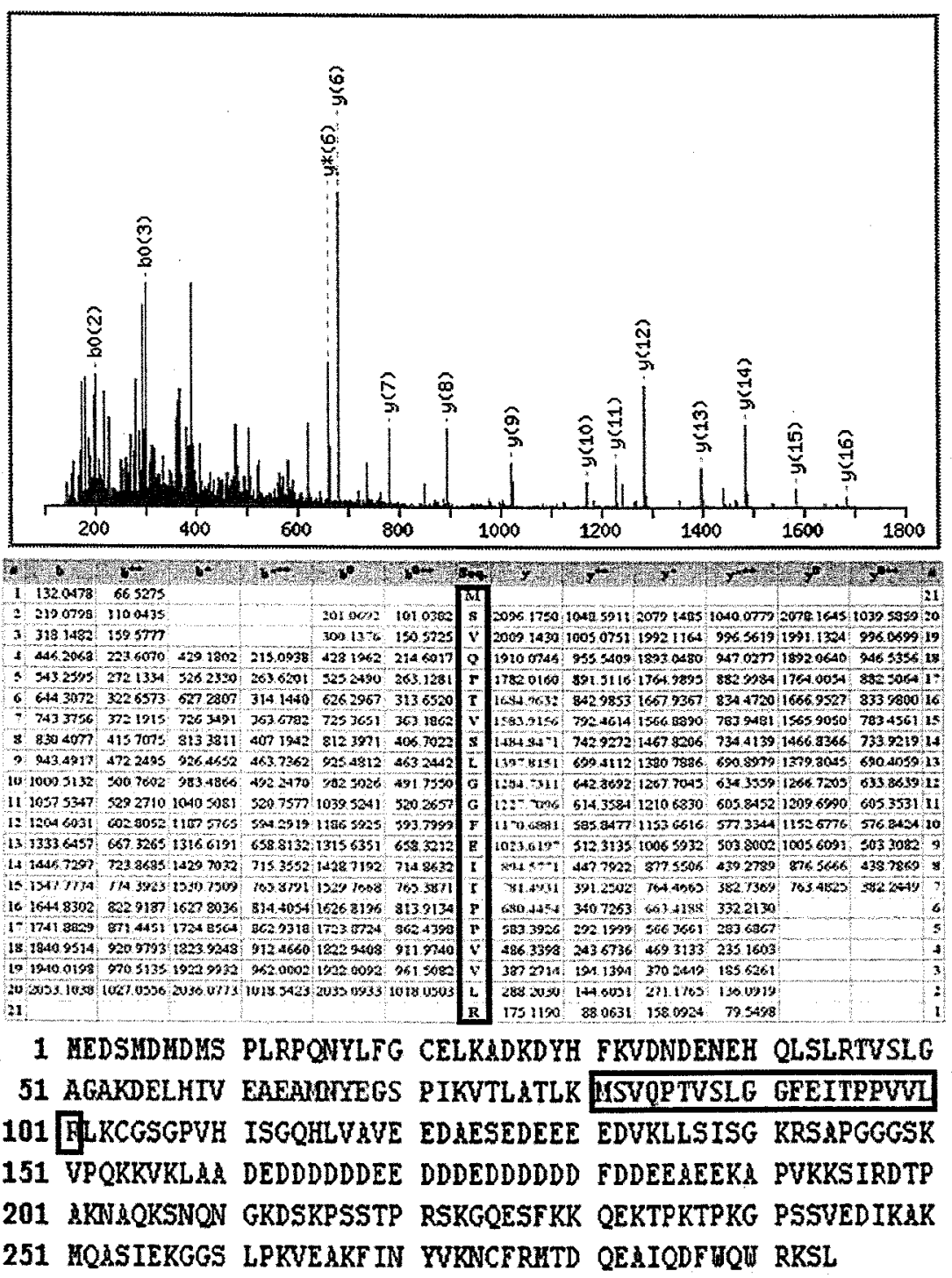

Fig. 2. ESI-Q-TOF-MS analysis of differential protein spot 12 . The amino acid sequence of a doubly charged peptide with a $m / z$ of 1113.7327 was identified as MSVQPTVSLGGFEITPPVVLR based on mass differences in the y-fragment ions series, and matched with residues $81-101$ of Nucleophosmin.

two cell lines. Sixteen of these protein spots were identified by ESI-Q-TOF mass spectrometry, and 3 proteins were identified by Western blot analysis using commercially available antibodies. We further validated the function of Nucleophosmin in drug resistance, and found that its overexpression contributes considerably to the development of MDR in SGC7901/ADR. These findings illustrate that multiple mechanisms are involved in the development of drug resistance in gastric cancer cells, and that these different mechanisms may all contribute to chemotherapeutic resistance in the treatment of gastric cancer.

Nucleophosmin (NPM1), also known as B23, was originally identified as a nonribosomal nucleolar phosphoprotein found at high levels in the granular regions of the nucleolus (Yung $e t$ al., 1985). NPM1, which is highly conserved in vertebrates and widely distributed among different species, has a molecular weight of 35 to $40 \mathrm{kDa}$ and $\mathrm{pI}$ of 5.1 to 5 (Chang and Olson, 1990). NPM1 is a multifunctional protein that is involved in an array of biological and pathological processes. For example, NPM1 can shuttle between the nucleus and cytoplasm during the cell cycle (Szebeni et al., 1995), and it has been proposed that this shuttling ability is related to its molecular chaperone activities, such as the prevention of protein aggregation and the protection of enzymes during thermal denaturation (Szebeni and Olson, 1998). In light of the potential role of NPM1 as a chaperone, it is conceivable that NPM1 may have an important role in helping cells survive environmental stresses, such as drug attack.

It has also been suggested that NPM1 plays an important role in regulation of the nucleolar function for cellular differentiation and apoptosis. NPM1 antisense oligomer treatment not only significantly potentiated retinoic acid 

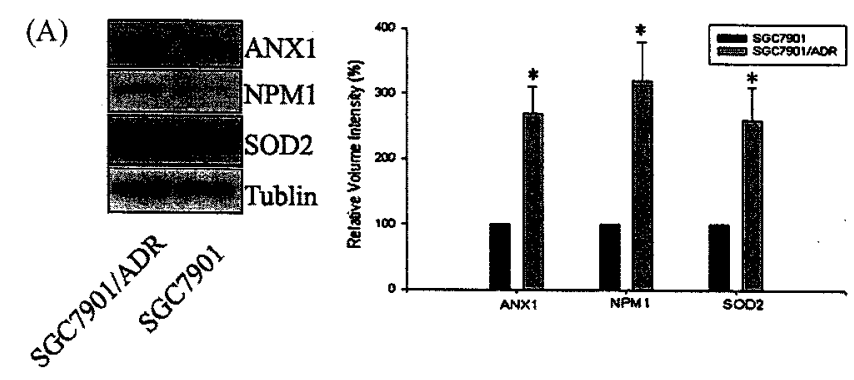

(B)

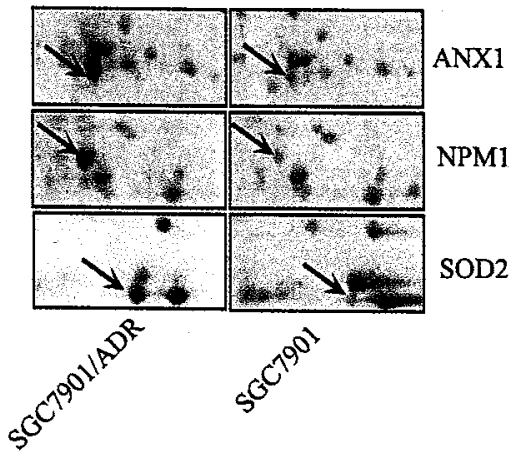

Fig. 3. A representative result showing changes in the expression levels of Annexin1 (ANX1), Nucleophosmin (NPM1) and Superoxide dismutase [Mn] (SOD2) in SGC7901 and SGC7901/ ADR by Western blot analysis(A) and 2-DE (B). Western blot analysis was repeated in triplicate. Bars, SE. *, a $p \leq 0.05$ indicates a significant difference from the control SGC7901 cell line as determined by a $t$-test.

(RA)-induced cellular differentiation, but also significantly potentiated sodium butyrate (BuONa)-induced apoptosis of HL-60 leukemia cells (Liu et al., 1998; Hsu et al., 1998). A search for genes involved in ultraviolet (UV) resistance in human cells as a result of mRNA differential display revealed that expression of NPM1 mRNA was induced by UV irradiation in UV-resistant cells, but not in control UVsensitive cells (Higuchi et al., 1998). Wu et al. (2002) also demonstrated that NPM1 mRNA was increased after UV irradiation in parental HeLa cells. Additionally, transfection of HeLa cells with NPM1 antisense cDNA increased cellular sensitivity to UV-induced cell death (Wu et al., 2002). In this study, NPM1 was found to be overexpressed in SGC7901/ ADR, however, when its expression in SGC7901/ADR was suppressed by NPM1 siRNA the cells exhibited increased sensitivity to adriamycin. These results indicated that the overexpression of NPM1 was involved in the MDR phenotype of SGC7901/ADR, possibly by inhibiting adriamycin-induced cell apoptosis. Therefore, NPM1 might be a new target protein for reversing MDR.

One of the major proteins groups that was expressed differentially between SGC7901/ADR and SGC7901 were chaperones, including members of the heat shock proteins family, such as HSC70, HSPA9B and GRP78. Among them, GRP78 is associated with the MDR phenotype of many types of cancer cells. GRP78 can protect cells against apoptotic

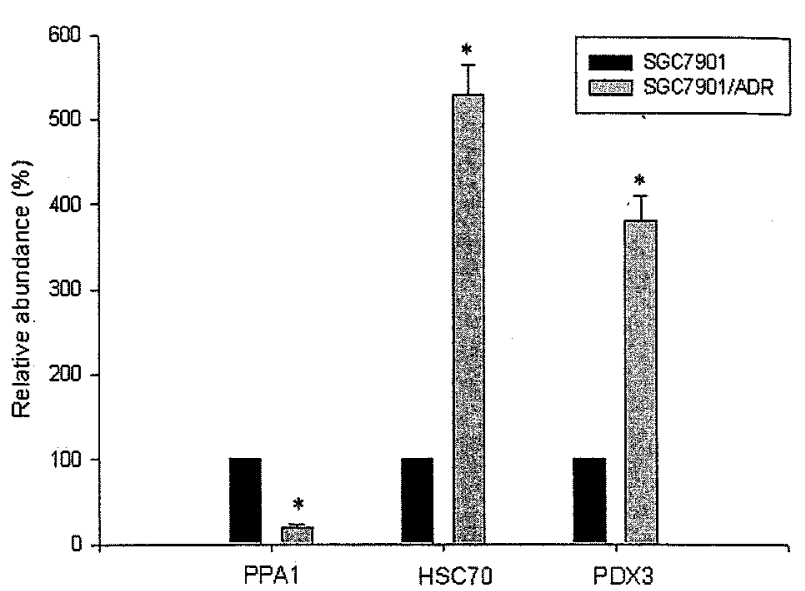

Fig. 4. Relative mRNA expression levels of PPA1, HSC70 and PDX3 between SGC7901 and SGC7901/ADR after normalization with GAPDH mRNA levels as determined by real-time RT-PCR. Real-time quantitative RT-PCR analysis was repeated at least three times. Bars, SE. *, a $p \leq 0.05$ indicates a significant difference from the control SGC7901 cell line as determined by a $t$-test.

death by preventing the formation of a functional apoptosome (Reddy et al., 1999), and also complexes with caspase-7 to form an antiapoptotic complex (Reddy et al., 2003). In this study, GRP78 was up-regulated in SGC7901/ADR, which further indicates that differential expression of GRP78 is correlated with MDR in SGC7901/ADR.

Two calcium binding proteins were also differentially expressed in SGC7901/ADR. The annexins are a calciumbinding protein family and their function is not well understood. Although overexpression of annexin 1 in a gastric carcinoma cell line that was resistant to daunorubicin was reported by Sinha et al. (Sinha et al., 1998), annexin 1 has not been correlated with MDR. Reticulocalbin-1 (RCN) is an endoplasmic reticulum-resident calcium-binding protein. Hirano et al. (2005) used 2-DE analysis to show that decreased expression in RCN was associated with the acquisition of CDDP-drug resistance, and that an RCN-transfectant of a lung cancer H69 CDDP-resistant strain showed intermediate sensitivity between the parent strain and the CDDP-resistant strain (Hirano et al., 2005). In this study, an obvious downregulation of RCN was apparent in SGC7901/ADR, which indicates that decreased expression of RCN is correlated with MDR in cancer cells.

Antioxidants have been closely correlated with the development of MDR. Superoxide dismutase [Mn] (SOD2) and Superoxide dismutase [Cu-Zn] (SOD1) are mitochondrial antioxidative enzymes that dismutate the superoxide free radicals to hydrogen peroxide and molecular oxygen. Numerous studies have shown that SOD can protect against pro-oxidant insults resulting from cytokine treatment, ultraviolet light, irradiation, certain tumors, and ischemia/reperfusion (Macmillan-Crow and Cruthirds, 2001). Our results showed that SOD1 and SOD2 were overexpressed in SGC7901/ADR, which indicated that 
(A)

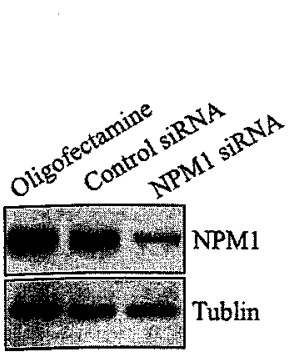

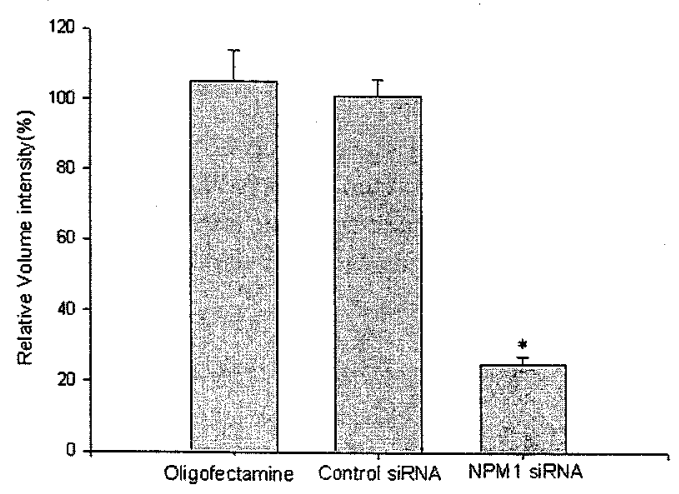

(D)

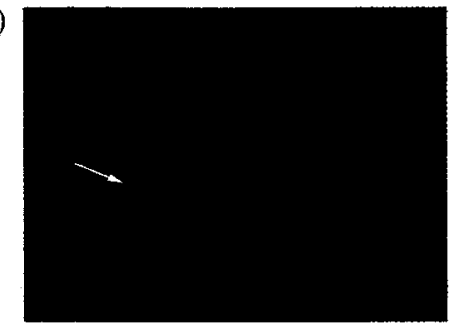

NPM1 siRNA

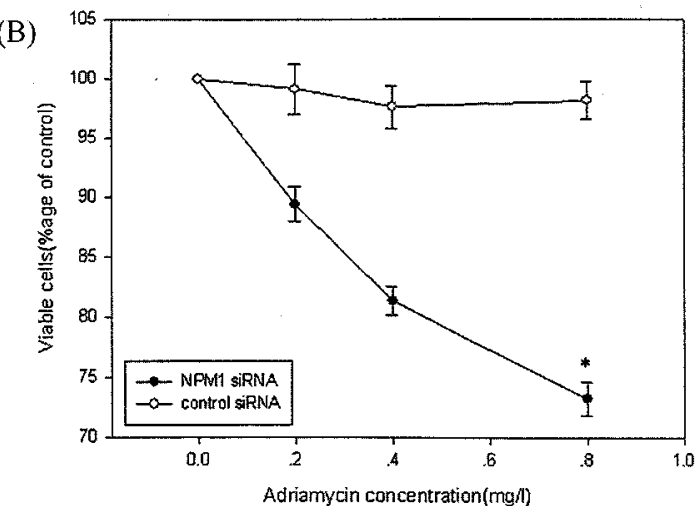

(C)

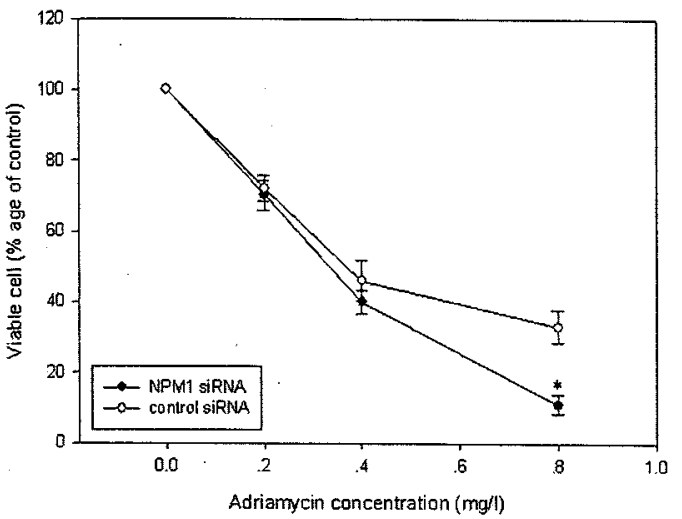

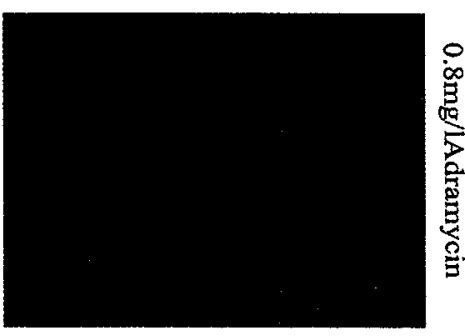

Control siRNA

Fig. 5. The effect of Nucleophosmin (NPM1) siRNA treatment on adriamycin chemosensitivity in SGC7901/ADR cells. (A) Western blot analysis showed that treatment of SGC7901/ADR cells with NPM1 siRNA significantly reduced Nucleophosmin protein levels (approximately $75 \%$ ), whereas Nucleophosmin protein expressions was not significantly suppressed by control siRNA and oligofectamine. Oligofectamine (a cationic lipid, Invitrogen, Carlsbad, CA, USA), cells treated with oligofectmine only. (B) MTT assay showing that NPM1 siRNA transfection could significantly decrease the cell viability of SGC7901/ADR cells incubated with adriamycin. (C) MTT assay showing that NPM1 siRNA transfection could significantly decrease the cell viability of SGC7901 cells incubated with adriamycin. The experiment was repeated in triplicate. Points, mean viable cells (\% of control) from three experiments; bars, SE. *, a $p \leq 0.05$ indicates a significant difference from control siRNA as determined by a $t$-test. (D) The nuclear morphology of cells was studied using the cellpermeable DNA dye Hoechst 33258. Apoptotic nuclei showing intense fluorescence corresponding to chromatin condensation (arrow) are indicated. After being treated for $48 \mathrm{~h}$ with $0.8 \mathrm{mg} / \mathrm{l}$ adriamycin, SGC7901/ADR cells that were transfected with NPM1 siRNA exhibited features indicative of apoptosis, whereas no obviously condensed nuclei were observed in control siRNA transfected SGC7901/ADR cells.

both proteins might be associated with the adriamycin resistant phenotype in SGC7901/ADR. Finally, there were still some proteins, including proteins related to metabolic enzymes and signal transduction that were found to be differentially expressed in SGC7901/ADR and SGC7901, but have not previously been linked to MDR. The correlation between these proteins and MDR in SGC7901/ADR requires further study.

In summary, using a proteomic approach, we identified 16 protein spots that were expressed differentially in SGC7901/ ADR and SGC7901. Association of NPM1, one of the upregulated proteins in SGC7901/ADR, with MDR was verified using NPM1 siRNA. These findings may have important clinical implications. Additionally, future studies of the other identified proteins using similar strategies may yield equally important information regarding their role in drug resistance. All of the proteins in this study, including NPM1, may be developed as new targets for better treatment of cancers using combination chemotherapy.

\section{References}

An, H. Z., Zhou, S. J. and Fan, D. M. (1997) Establishment and characteristics of an adriamycin resistant human gastric carcinoma cell line. Xiandai Xiaohua Bing Ji Neijing Zazhi 2, 108-110.

Candiano, G., Bruschi, M., Musante, L., Santucci, L., Ghiggeri, G. M., Carnemolla, B., Orecchia, P., Zardi, L. and Righetti, P. G. (2004) Blue silver: a very sensitive colloidal Coomassie G-250 staining for proteome analysis. Electrophoresis 25, 1327-1333.

Chang, J. H. and Olson, M. O. (1990) Structure of the gene for rat nucleolar protein B23. J. Biol. Chem. 265, 18227-18233.

Depeille, P., Cuq, P., Passagne, I., Evrard, A. and Vian, L. (2005) Combined effects of GSTP1 and MRP1 in melanoma drug resistance. Br. J. Cancer 93, 216-223.

Hong, L., Piao, Y., Han, Y., Wang, J., Zhang, X., Du, Y., Cao, S., Qiao, T., Chen, Z. and Fan, D. (2005) Zinc ribbon domaincontaining 1 (ZNRD1) mediates multidrug resistance of leukemia cells through regulation of $\mathrm{P}$-glycoprotein and Bcl-2. Mol. Cancer 
Ther. 4, 1936-1942.

Hsu, C. Y. and Yung, B. Y. M. (1998) Down-regulation of nucleophosmin/B23 during retinoic acid-induced differentiation of human promyelocytic leukemia HL-60 cells. Oncogene 16, 915-923.

Higuchi, Y., Kita, K., Nakanishi, H., Wang, X. L., Sugaya, S., Tanzawa, H., Yamamori, H., Sugita, K., Yamaura, A. and Suzuki, N. (1998) Search for genes involved in UV-resistance in human cells by mRNA differential display: increased transcriptional expression of nucleophosmin and T-plastin genes in association with the resistance. Biochem. Biophys. Res. Commun. 248, $597-$ 602.

Hirano, T., Kato, H., Maeda, M., Gong, Y., Shou, Y., Nakamura, M., Maeda, J., Yashima, K., Kato, Y., Akimoto, S., Ohira, T., Tsuboi, $M$. and Ikeda, N. (2005) Identification of postoperative adjuvant chemotherapy responders in non-small cell lung cancer by novel biomarker. Int. J. Cancer 117, 460-468.

Kramer, R. A., Zakher, J. and Kim, G (1998) Role of glutathione redox cycle in acquired and de novo multidrug resistance. Science 241, 694-697.

Lee, J. T. Jr., Steelman, L. S. and McCubrey, J. A. (2004) Phosphatidylinositol 3'-kinase activation leads to multidrug resistance protein-1 expression and subsequent chemoresistance in advanced prostate cancer cells. Cancer Res. 64, 8397-8404.

Lelong-Rebel, I. H. and Cardarelli, C. O. (2005) Differential phosphorylation patterns of P-glycoprotein reconstituted into a proteoliposome system: insight into additional unconventional phosphorylation sites. Anticancer Res. 25, 3925-3935.

Livak, K. J. and Schmittgen, T. D. (2001) Analysis of relative gene expression data using real-time quantitative PCR and the 2(-Delta Delta C(T)) Method. Methods 25, 402-408.

Liu, W. H. and Yung, B. Y. M. (1998) Mortalization of human promyelocytic leukemia HL-60 cells to be more susceptible to sodium butyrate-induced apoptosis and inhibition of telomerase activity by down-regulation of nucleophosmin/B23. Oncogene 17, 3055-3064

Moscow, J. A. and Cowan, K. H. (1998) Multidrug resistance. J. Natl. Cancer. Inst. 80, 14-20.

Macmillan-Crow, L. A. and Cruthirds, D. L. (2001) Invited review: manganese superoxide dismutase in disease. Free Radic. Res. 34, 325-336.

Plumb, J. A., Milroy, R. and Kaye, S. B. (1989) Effects of the pH dependence of 3-(4,5-dimethylthiazol-2-yl)-2,5-diphenyl-tetrazolium bromide-formazan absorption on chemosensitivity determined by a novel tetrazolium-based assay. Cancer Res. 49, 4435-4440.

Perez-Ortiz, J. M., Tranque, P., Vaquero, C. F., Domingo, B., Molina, F., Calvo, S., Jordan, J., Cena, V. and Llopis, J. (2004) Glitazones differentially regulate primary astrocyte and glioma cell survival.
Involvement of reactive oxygen species and peroxisome proliferator-activated receptor-gamma. J. Biol. Chem. 279, 89768985.

Reddy, R. K., Lu, J. and Lee, A. S. (1999) The endoplasmic reticulum chaperone glycoprotein GRP94 with $\mathrm{Ca}(2+)$-binding and antiapoptotic properties is a novel proteolytic target of calpain during etoposide-induced apoptosis. J. Biol. Chem. 274, 2847628483.

Reddy, R. K., Mao, C., Baumeister, P., Austin, R. C., Kaufman, R. J. and Lee, A. S. (2003) Endoplasmic reticulum chaperone protein GRP78 protects cells from apoptosis induced by topoisomerase inhibitors: role of ATP binding site in suppression of caspase-7 activation. J. Biol. Chem. 278, 20915-20924.

Stein, W. D., Robey, R., Cardarelli, C., Gottesman, M. M. and Bates, S. E. (2003) Low and high concentrations of the topo II inhibitor daunorubicin in NIH3T3 cells: reversible G2/M versus irreversible G1 and S arrest. Cell Cycle 2, 134-142.

Szebeni, A., Herrera, J. E. and Olson, M. O. (1995) Interaction of nucleolar protein B23 with peptides related to nuclear localization signals. Biochemistry 34, 8037-8042.

Szebeni, A. and Olson, M. O. (1998) Nucleolar protein B23 has molecular chaperone activities. Protein Sci. 8, 905-912.

Sinha, P., Hutter, G., Kottgen, E., Dietel, M., Schadendorf, D. and Lage, H. (1998) Increased expression of annexin I and thioredoxin detected by two-dimensional gel electrophoresis of drug resistant human stomach cancer cells. J. Biochem. Biophys. Methods. 37, 105-116.

Wang, Y. J., Zhang, G. Y., Xiao, Z. Q., Wang, H. M. and Chen, Z. C. (2006) Preliminary proteomic analysis of indomethacin's effect on tumor transplanted with colorectal cancer cell in nude mice. $J$. Biochem. Mol. Biol. 39, 171-177.

Wu, M. H., Chang, J. H., Chou, C. C. and Yung, B. Y. (2002) Involvement of nucleophosmin/B23 in the response of HeLa cells to UV irradiation. Int. J. Cancer 97, 297-305.

Yeh, J. J., Hsu, N. Y., Hsu, W. H., Tsai, C. H., Lin, C. C. and Liang, J. A. (2004) Comparison of chemotherapy response with Pglycoprotein, multidrug resistance-related protein-1, and lung resistance-related protein expression in untreated small cell lung cancer. Lung 183, 177-183.

Yung, B. Y., Busch, H. and Chan, P. K. (1985) Translocation of nucleolar phosphoprotein $\mathrm{B} 23(37 \mathrm{kDa} / \mathrm{pI} 5.1)$ induced by selective inhibitors of ribosome synthesis. Biochim. Biophys. Acta 826, 167-173.

Zhao, Y., You, H., Liu, F., An, H., Shi, Y., Yu, Q. and Fan, D. (2002) Differentially expressed gene profiles between multidrug resistant gastric adenocarcinoma cells and their parental cells. Cancer Lett. 185, 211-218. 